\title{
Simulation of OWES with Five-Level Converter Linked to the Grid: Harmonic Assessment
}

\author{
M. Seixas, R. Melício and V.M.F. Mendes \\ IDMEC/LAETA-Instituto Superior Técnico \\ Universidade de Lisboa and Departamento de Física Escola \\ de Ciências e Tecnologia, Universidade de Évora, Portugal \\ ruimelicio@gmail.com
}

\author{
V.M.F. Mendes and C. Couto, Senior Member, IEEE \\ Instituto Superior de Engenharia de Lisboa, C-MAST \\ Center for Mechanical and Aerospace Sciences and \\ Technology and Centro Algoritmi University of Minho, \\ Lisbon and Guimarães, Portugal
}

\begin{abstract}
This paper deals with a computing simulation for an offshore wind energy system taking into account the influence of the marine waves action throughout the floating platform. The wind energy system has a variable-speed turbine equipped with a permanent magnet synchronous generator and a full-power fivelevel converter, injecting energy into the electric grid through a high voltage alternate current link. A reduction on the unbalance of the voltage in the DC-link capacitors of the five-level converter is proposed by a strategic selection of the output voltage vectors. The model for the drive train of the wind energy system is a two mass model, including the dynamics of the floating platform. A case study is presented and the assessment of the quality of the energy injected into the electric grid is discussed.
\end{abstract}

Keywords-Offshore Wind Energy System; five-level converter; modelling; simulation.

\section{INTRODUCTION}

The development of the society in the last decades has lead to a progressive increase in energy usage. The conventional energy sources such as coal, oil, natural gas and nuclear have been used as the main usage for conversion into electric energy [1]. However, conventional energy sources have been criticized as having issues pointing to adverse circumstances that hinder consider reliable energy sources for a sustainable society development. For instances, the issue regarding the: harmful to the habitat, coal and fuel combustion process produces pollution, emissions of gas contributing to the increase of the global warming [2]; unstable price of fuel having depletion foreseen in less than a century. Renewable energy sources emerge as a response to the issues pointed to be adverse circumstances of conventional energy sources. The usage-based of renewable energy technology has increased by $30 \%$ to $40 \%$ per year worldwide [3] and wind power has become the fastest growing renewable energy power generation technology in the world [4]. Currently, the wind power generation solely accounts for $27 \%$ of annual growth rate [3]. At present, more than 40 countries in the World have wind turbines installed, mostly located in Europe, North America, and East Asia [4]. Nowadays, due to this growth there is an increasing difficulty to find new appropriate places for deployment of onshore wind farms. Particularly, this difficult to find appropriate places is a fact in Europe [5].
Thus, there is an interest in the development of offshore wind energy systems (OWES), which has the benefits of available vast sea areas and of more favorable wind conditions, than those on onshore [6]. Also, there is an interest devoted to the efficiently incorporation of the wind power generation into the electric grid. The efficient incorporation of wind power generation into the electric grid implies the use of a power electronic interface and power electronic devices are damned to inject harmonic. Harmonics create significant interference with communication systems, cause excessive heating in rotating machinery, increase power system losses, damage sensitive loads, and generate noise on regulating devices and control systems [7]. Nevertheless, the power converter is an unavoidable essential constituent of a wind power generation systems. A power converter increase on the number of voltage levels leads to better power quality waveforms [8], decreases the total harmonic distortion (THD) [9]. A five-level power converter is particularly interesting for equipping high power systems, because the implemented number of unidirectional commanded insulated gate bipolar transistors (IGBTs) allows each one to be subjected to a lower voltage. Nevertheless, as more and more wind power generation systems are connected to the electric grid, the harmonic content has to be taken into consideration or the power quality in the electric grid may become threatened [10]. Thus, the THD for wind power generation systems has to be assessed to ensure that dynamic actions influencing the operation do not lead to violation of standards of quality of energy injected into the electric grid.

This paper presents a model for an OWES equipped with permanent magnet synchronous generator (PMSG) and backto-back MPC five-level converter topology, with unidirectional commanded IGBTs. The focus of the paper is on the converter performance and not on the control dynamics. The OWES is linked to the electric grid by alternated current (AC) power transmission. A two mass (TM) model, modeling the dynamics of the rotor, the structure and the floating platform models the drive train. The first mass models the mechanical inertia subjected to the action of the wind and the marine waves; the second mass is due to the inertia of the generator. Classical proportional integral (PI) controllers are use to obtain the reference values. Also, pulse width modulation (PWM) by space vector modulation (SVM) 


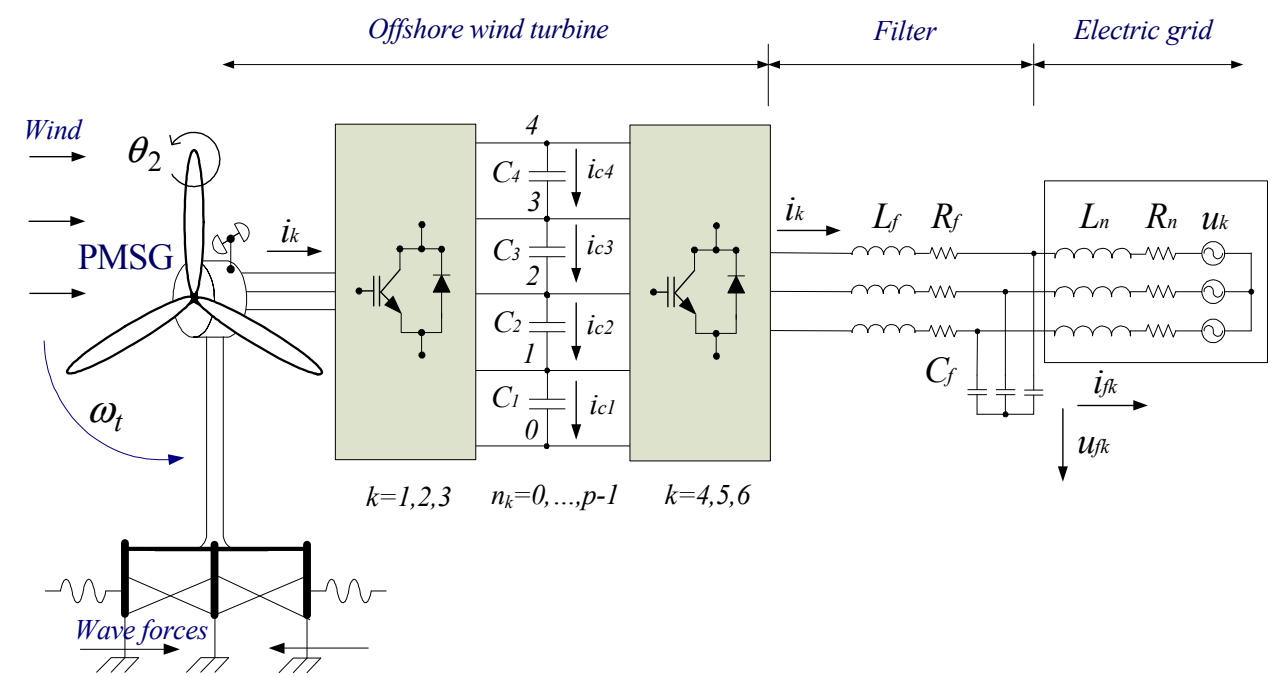

Fig. 1. Offshore wind energy system with five-level converter, AC.

associated with sliding mode (SM) is used for trigger the converter's IGBTs. The rest of the paper is organized as followed: Section II presents the mechanical models and the electric models for the five-level converter AC power transmission, the filter and the electric grid. Section III presents the control strategy and the selection of the output voltage vectors. Section IV presents the case study simulated in Matlab/Simulink and some of the output results particularly concerned with the harmonic content. Section V presents concluding remarks.

\section{MODELING}

The model for the wind speed variation reported in [11] is used in this paper. The OWES model considers two sources of actions. The wind speed causes one of the actions and the floating platform motion causes another one, by acting on the structure of the wind turbine. The first action has an energy conversion and a perturbation, i.e., a mechanical torque oscillation, and the second one is regarded as a perturbation. Both actions are sources for electrical perturbation. The configuration of the simulated OWES with five-level power converter AC power transmission is shown in Fig. 1.

\section{A. Mechanical Modeling}

Although the wind speed intermittence and variability has a stochastic character, for the assessment in this paper is possible to use a deterministic modeling for the wind speed as a sum of harmonics ranging $0.1-10 \mathrm{~Hz}$ [11] given by

$$
u(t)=u_{o}\left[1+\sum_{k} A_{k} \sin \left(\omega_{k} t\right)\right]
$$

where $u$ is the wind speed with perturbation, $u_{o}$ is the average wind speed, $A_{k}$ is the magnitude of the $k$ eigenswing, $\omega_{k}$ is the eigenfrequency of the $k$ eigenswing.
The mechanical power captured by the wind turbine without perturbations is given by

$$
P_{b}=\frac{1}{2} \rho S u^{3} C_{p}
$$

where $P_{b}$ is the turbine mechanical power without dynamics influences, $\rho$ is the air density, $S$ is the area covered by the turbine blades, $C_{p}$ is the power coefficient.

The analytic function for the power coefficient $C_{p}$ as a function of the tip speed ratio (tsr) [12] is shown in Fig. 2.

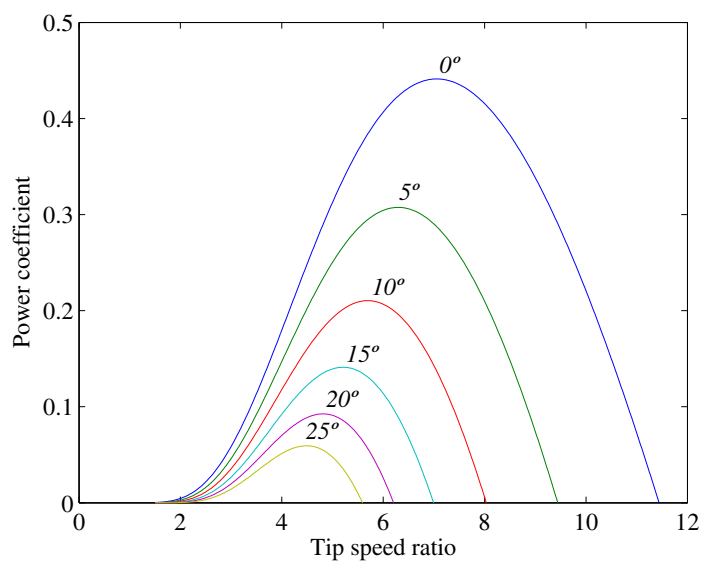

Fig. 2. Power coefficient versus tsr.

The mechanical power captured from the wind turbine with the perturbations is given by

$$
P_{t}=P_{b}\left[1+\sum_{n=1}^{3} I_{n}(t)\right]
$$


where $I_{n}$ are the dynamics influences considered [11,13]: asymmetry in the turbine, vortex tower interaction and eigenswings in the blades modeled.

The marine waves are responsible for the floating platform motion. The marine wave model [14] is given by

$$
\eta(x, y, t)=\sum_{i=1}^{n} \eta_{a}(i) \cos [\vartheta(i) t+\zeta(i)-\phi(i) v(x, y, t)]
$$

where

$$
v(x, y, t)=x \cos (\psi(i))+y \sin (\psi(i))
$$

where $\eta$ is the wave height for $x, y$ position as a function of time, $\eta_{a}$ is the vector of harmonic wave amplitudes, $\vartheta$ is the vector of harmonic wave frequencies, $\zeta$ is the vector of harmonic wave phases (random), $\phi$ is the vector of harmonic wave numbers, $\psi$ is the vector of harmonic wave directions.

The behavior of the mechanical drive train of a OWES can be considered by modeling the inertial mass as a set of discrete inertia ones connected together by springs and dampers. A TM model is the one followed in this paper. The configuration of the simulated TM drive train model is shown in Fig. 3.

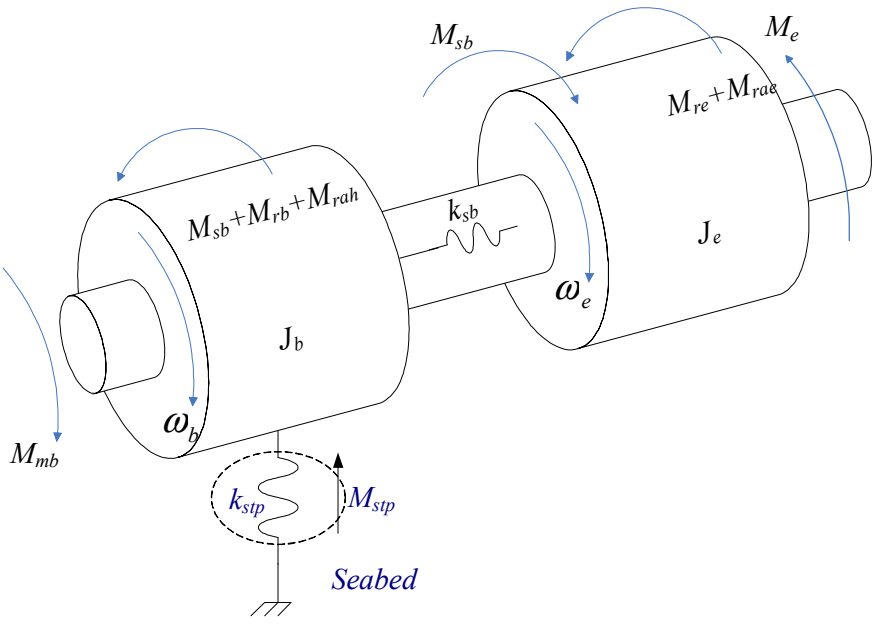

Fig. 3. Two mass drive train model.

The equations for modeling the motion of the rotor for the TM drive train are based on the second law of Newton torsional version, given by

$$
\begin{gathered}
\frac{d \omega_{b}}{d t}=\frac{1}{J_{b}}\left(M_{m b}+M_{s t p}-M_{r b}-M_{r a h}-M_{s b}\right) \\
\frac{d \omega_{e}}{d t}=\frac{1}{J_{e}}\left(M_{s b}-M_{r e}-M_{r a e}-M_{e}\right)
\end{gathered}
$$

where $\omega_{b}$ is the rotor angular speed of the turbine, $J_{b}$ is the moment of inertia intended to describe the mechanical inertia subjected to the action of the wind and the marine waves, $M_{m b}$ is the wind turbine mechanical torque, $M_{s t p}$ is the tower and platform stiffness torque due to floating platform motion, $M_{r b}$ is the turbine bearing resistant torque, $M_{r a h}$ is the hub and blades viscosity airflow resistant torque, $M_{s b}$ is the shaft stiffness torsional torque, $\omega_{e}$ is the angular speed of the generator, $J_{e}$ is the generator moment of inertia, $M_{r e}$ is the generator bearing resistant torque, $M_{\text {rae }}$ is the generator viscosity airflow resistant torque, $M_{e}$ is the electric torque associated with the power outputted by the generator.

\section{B. Electric Modeling}

The equations of the behavior of a PMSG can be retrieved in diverse texts [15]. The need to avoid demagnetization of the permanent magnet of the PMSG is imposed by assuming a null value reference for the stator direct component current, i.e., $i_{s d}^{*}=0$ is imposed [16].

The five-level converter is an AC-DC-AC power converter, equipped with twenty four unidirectional commanded IGBTs, identified by $S_{i k}$ implementing the rectifier, and with the same number of unidirectional commanded IGBTs implementing the inverter. The rectifier is connected between the PMSG and a voltage divider constitute by four capacitor banks. The inverter is connected between these capacitor banks and a second order filter, which in turn is connected to an electric grid. The groups of height IGBTs linked to the same phase constitute the arm $k$ of the converter.

The converter has $p=5$ voltage levels. The voltage level on each phase is associated with the switching variable $n_{k}$ which range from 0 to $(p-1)$ and is used to identify the state of the IGBT $i$ in the leg $k$ of the converter establishing the switching function of each IGBT. The index $i$ with $i \in\{1, \ldots, 8\}$ identifies the IGBT. The switching states combinations of the IGBTs (conduction or blockage) of each arm $k$, determine the level variable $\delta_{j n_{k}}$ that is associated with the charging state of each capacitor bank. The level variable [17] is given by

$$
\delta_{j n_{k}}=\left\{\begin{array}{ll}
0 & j>n_{k} \\
1 & j \leq n_{k}
\end{array} \quad j \in\{1, \ldots, p-1\}, \quad n_{k} \in\{0, \ldots, p-1\}\right.
$$

The rectifier output voltage $u_{s k}$ as a function of each capacitor voltage $U_{c j}$ and of $\delta_{j n_{k}}$ for $j \in\{1, \ldots, p-1\}$, $n_{k} \in\{0, \ldots, p-1\}$ and $\delta_{j n_{k}} \in\{0,1\}$ is given by

$$
u_{s k}=\frac{1}{3} \sum_{j=1}^{p-1}\left(2 \delta_{j n k}-\sum_{\substack{l=1 \\ l \neq k}}^{3} \delta_{j n k}\right) U_{c j} \quad k \in\{1,2,3\}
$$


The inverter input voltage is given by an identical function as the one given in (9), but with $k \in\{4,5,6\}$.

The current on each capacitor bank $i_{c j}$ [17] as a function of $\delta_{j n_{k}}$ for $j \in\{1, \ldots, p-1\}, n_{k} \in\{0, \ldots, p-1\}$ and $\delta_{j n_{k}} \in\{0,1\}$ is given by

$$
i_{c j}=\sum_{k=1}^{3} \delta_{n k} i_{k}-\sum_{k=4}^{6} \delta_{n k} i_{k} \quad k \in\{1, \ldots, 6\}
$$

The voltage $U_{d c}$ is the sum of the capacitor voltages $U_{c 1}$, $U_{c 2}, U_{c 3}, U_{c 4}$, in the capacitor banks $C_{1}, C_{2}, C_{3}, C_{4}$. This voltage $U_{d c}$ is modeled by the state equation given by

$$
\frac{d U_{d c}}{d t}=\sum_{j=1}^{p-1} \frac{1}{C_{j}} i_{c j} \quad j \in\{1, \ldots, p-1\}
$$

A three-phase active symmetrical circuit in series models the electric grid [18]. The currents injected into the electric grid are modeled by the state equation given by

$$
\frac{d i_{f k}}{d t}=\frac{1}{L_{n}}\left(u_{f k}-R_{n} i_{f k}-u_{k}\right) \quad k \in\{4,5,6\}
$$

where $i_{f k}$ is the output of the filter, i.e., the currents injected into the electric grid, $u_{f k}$ is the voltage at the output of the filter, $L_{n}$ and $R_{n}$ are respectively the inductance and the resistance of the electric grid, $u_{k}$ is the equivalent voltage used to describe the electric grid as a three-phase active symmetrical circuit.

\section{CONTROL STRATEGY}

Classical PI controllers are used on the OWES and PWM by SVM associated with SM is used on the converters. SM is known by having robustness to model uncertainty and to external disturbances. The choice of the appropriate space vector is processed by the sliding mode control. Finite value of switching frequency of $2 \mathrm{kHz}, 5 \mathrm{kHz}$ or $10 \mathrm{kHz}$ are normally reported. The fact that the IGBTs have a finite switch frequency implies that an error $e_{\alpha \beta}$ will be expected between the reference value and the control value. Hence, to ensured that the system does not abandon the sliding surface $S\left(e_{\alpha \beta}, t\right)$ is proved that has to hold a stability conditions [19] given by

$$
S\left(e_{\alpha \beta}, t\right) \frac{d S\left(e_{\alpha \beta}, t\right)}{d t}<0
$$

In practice a small error $\varepsilon>0$ for $S\left(e_{\alpha \beta}, t\right)$ has to be allowed, due to IGBTs switching only at finite frequency, therefore the acceptance of an error window is feasible. This error window over time is the sliding surface and in practice the switching strategy is given by

$$
-\varepsilon<S\left(e_{\alpha \beta}, t\right)<+\varepsilon
$$

The values for the integer voltage variables $\sigma_{\alpha}$ and $\sigma_{\beta}$ are in a domain set, i.e., obey the relation given by

$$
\sigma_{\alpha}, \sigma_{\beta} \in\{-4,-3,-2,-1,0,1,2,3,4\}
$$

The integer variables $\sigma_{\alpha}$ and $\sigma_{\beta}$ allow choosing the most appropriate of the 125 vectors. The output vectors for level 0 , level 1, level 2, level 3 and level 4 in the $\alpha \beta$ plane for the five-level converter are shown in Fig. 4.

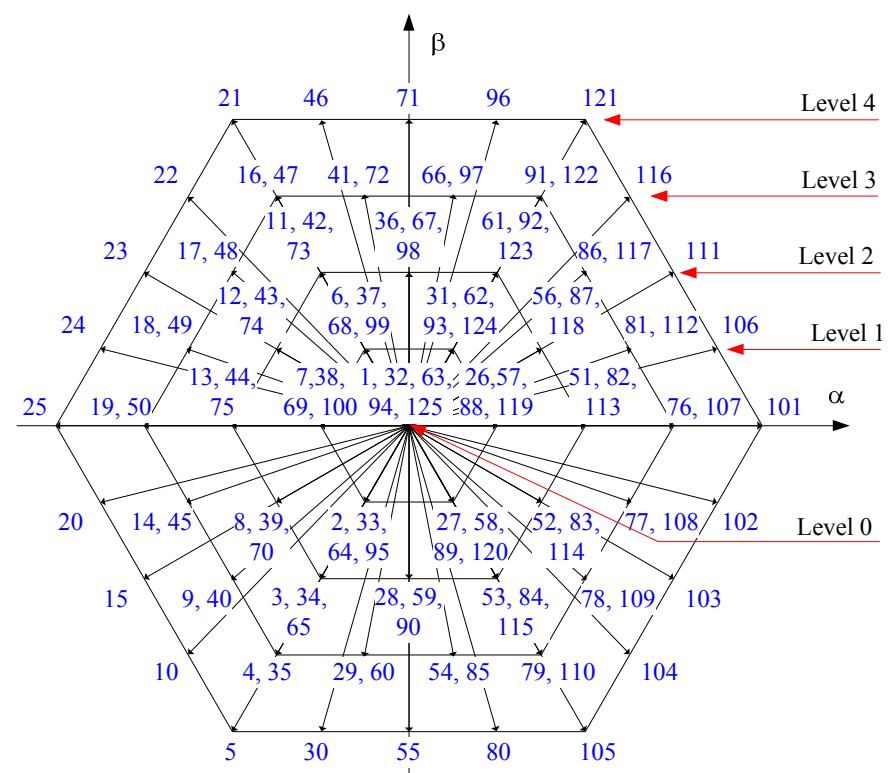

Fig. 4. Five-level converter, space vectors.

Fig. 4 shows the space vectors in order to mitigate the critical issue in multi-level converters related with the DC-link capacitors unbalance voltages [13].

\section{CASE STUdY}

The mathematical model for the OWES with the five-level converter is implemented in Matlab/Simulink.

The simulated OWES linked to the electric grid has a nominal power of $2 \mathrm{MW}$. The electric grid is considered to be $1 \mathrm{kV}$ at $50 \mathrm{~Hz}$.

The wind speed considered in the simulation has a profile defined by having an average speed starting with a value of $10 \mathrm{~m} / \mathrm{s}$ followed by a ramp increase stabilizing after $1.5 \mathrm{~s}$ with an average speed of the $20 \mathrm{~m} / \mathrm{s}$, i.e., between $1.5 \mathrm{~s}$ and $4 \mathrm{~s}$ the values for the average wind speed remain constant.

The significant wave height and the frequency are respectively $10 \mathrm{~m}$ and $0.25 \mathrm{~Hz}$. 
The average wind speed with the perturbations profile is shown in Fig. 5.

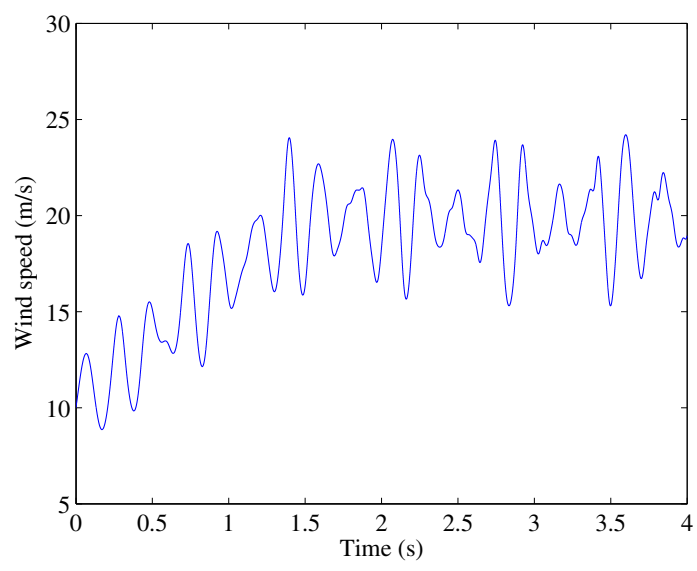

Fig. 5. Wind speed profile with perturbations.

The marine height elevation is shown in Fig. 6.

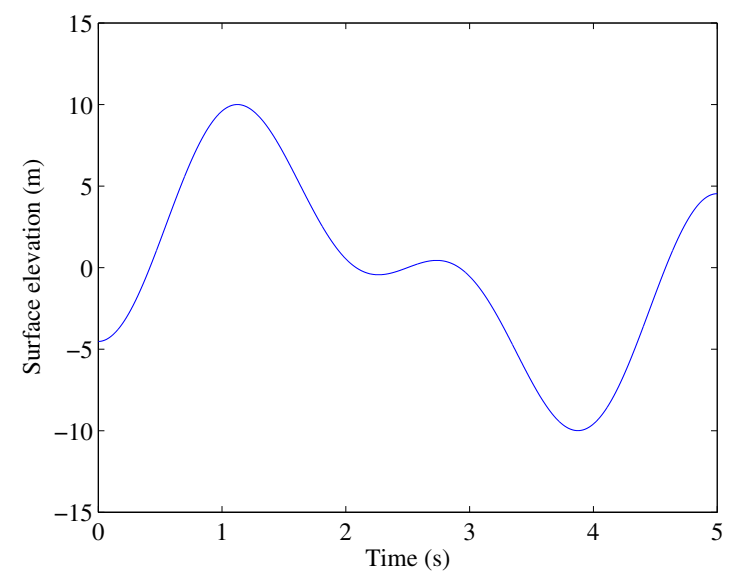

Fig. 6. Marine height elevation.

The results for the DC reference voltage and the voltage at the capacitor banks without unbalancing are shown in Fig. 7.

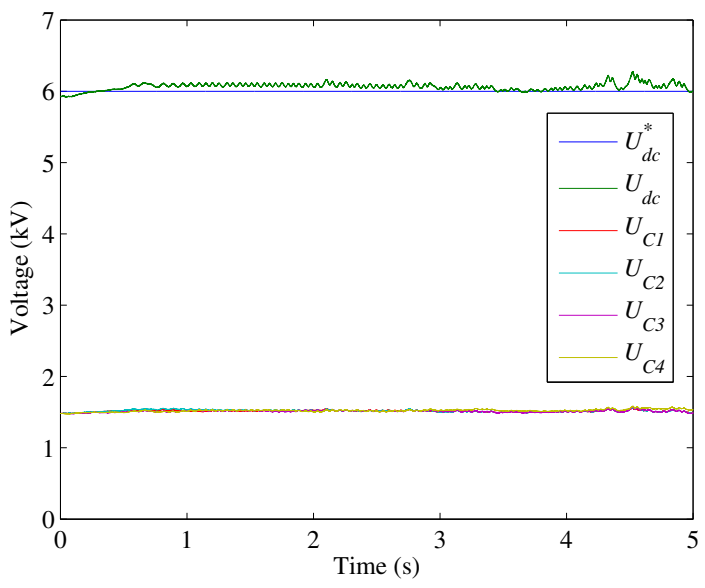

Fig. 7. DC voltages at capacitors without unbalancing.
The instantaneous current injected into the electric grid is shown in Fig. 8.

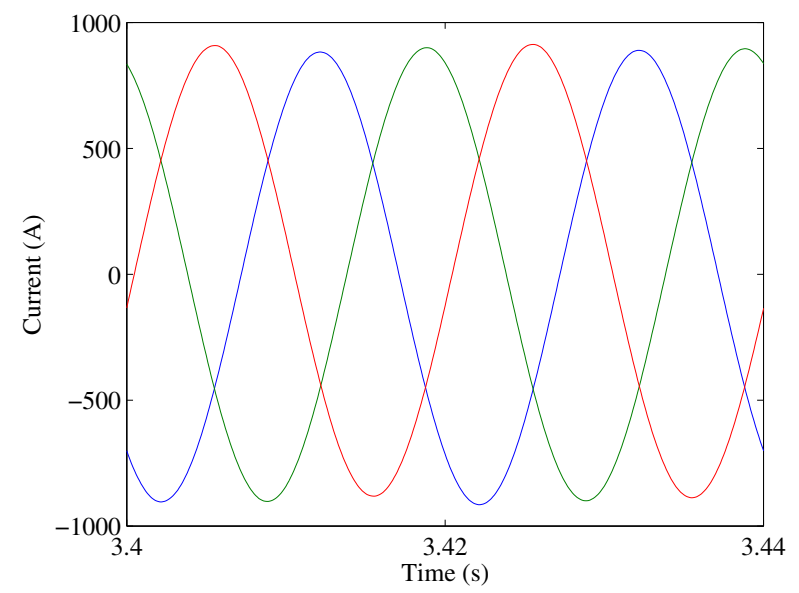

Fig. 8. Current injected in the electric grid.

Fig. 9 shows that the Fig. 8 current injected in the electric grid has a well-behavior, i.e., influence of marines waves is not propagate into the electric grid.

The Discrete Fourier Transform used to compute the total harmonic distortion THD is given by

$$
\operatorname{THD}(\%)=100 \frac{\sqrt{\sum_{H=2}^{50} X_{H}^{2}}}{X_{F}}
$$

where $X_{H}$ is the root mean square value of the harmonic $H$, $X_{F}$ is the root mean square value of the fundamental component. The THD of the current injected into the electric grid is shown in Fig. 9.

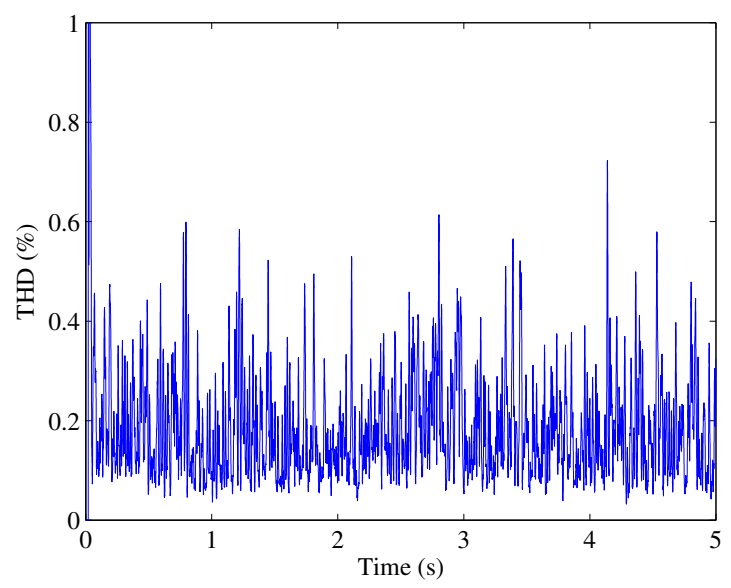

Fig. 9. THD of the current injected into the electric grid.

The average THD of the current injected into the electric grid for the five-level converter is $0.29 \%$. With the five-level converter, the THD of the output current is lower than the 5\% limit imposed by IEEE-519 standard [20]. 


\section{CONCLUSIONS}

The simulation of the electrical modeling of the five-level converter combined with the control strategy reveals the capability in mitigating the unbalancing between the capacitors bank voltages.

The simulation study revealed a good performance of the OWES with the five-level power converter. Although, there are effects on the current output of the power converter, the average value for the THD of the current injected into the electric grid is lower than 5\% limit imposed by IEEE-519 standard. The IEEE-519 standard might not be necessarily applicable in such situation. This standard is only used in this paper as a guideline for comparison purpose.

\section{ACKNOWLEDGMENT}

This work is funded by Portuguese Funds through the Foundation for Science and Technology-FCT under the: project LAETA 2015-2020, reference UID/EMS/50022/2013; FCT Research Unit $n^{\circ} 151$ C-MAST Center for Mechanical and Aerospace Sciences and Technology.

\section{REFERENCES}

[1] M. Tao, Y. Hongxing, and L. Lin, "A feasibility study of a stand-alone hybrid solar-wind-battery system for a remote island, " Applied Energy, vol. 121, pp 149-158, May 2014.

[2] T.F. Ishugaha, Y. Li, R.Z. Wang, and J.K. Kiplagat, "Advances in wind energy resource exploitation in urban environment: a review," Renewable and Sustainable Energy Reviews, vol. 37, pp 613-626, September 2014.

[3] H. Novanda, H. Regulski, P. Stanojevic, and V. Terzija "Assessment of frequency and harmonic distortions during wind farm rejection test," IEEE Trans. Sustainable Energy, vol. 4, pp 698-705, July 2013.

[4] J.H. Teng, R.C. Leou, C.Y. Chang, and S.Y. Chan, "Harmonic current predictors for wind turbines," Energies, vol. 6, pp 1314-1328, March 2013.

[5] T. Soukissian, "Use of multi-parameter distributions for offshore wind speed modeling: the Johnson $\mathrm{S}_{\mathrm{B}}$ distribution," Applied Energy vol 111, pp 982-1000, November 2013.

[6] B. Lange, S. Larsen, J. Højstrup, and R. Barthelmie, "Importance of thermal effects and sea surface roughness for offshore wind resource assessment," Journal of Wind Engineering and Industrial Aerodynamics, vol 92, pp 959-988, September 2004.
[7] L. Gidwani, "Grid connected PMSG wind turbine energy conversion systems," in: Recent Advances in Environmental Science, A. Kanarachos and N.E. Mastorakis, Eds. Lemenosos, Cyprus, 2013, pp. 15-20.

[8] S. Kouro, M. Malinowski, K. Gopakumar, J. Pou, L.G. Franquelo, B. Wu, J. Rodriguez, M.A. Pérez, and J.I. León, "Recent advances and industrial applications of multilevel converters,"IEEE Transactions on Industrial Electronics, vol. 57, pp. 2553-2580, July 2010.

[9] J. Rodriguez, S. Bernet, B. Wu, J.O. Pontt, and S. Kouro, "Multilevel voltage-source-converter topologies for industrial medium-voltage drives, " IEEE Transactions on Industrial Electronics, vol. 54, pp. 2930-2944, December 2007.

[10] F. Cucchiella, and I. Adamo, "Issue on supply chain of renewable energy," Energy Conversion and Management, vol. 76, pp. 774-780, December 2013.

[11] V. Akhmatov, H. Knudsen, and A.H. Nielsen, "Advanced simulation of windmills in the electric power supply," Int. J. Electr. Power Energy Systems, vol. 22, pp. 421-434, August 2000.

[12] G. Slootweg, H. Polinder, and W.L. Kling, "General model for representing variable speed wind turbines in power system dynamics simulations," IEEE Trans. Power Systems, vol. 18, pp. 144-151, February 2003.

[13] M. Seixas, R. Melício, and V.M.F. Mendes, "Fifth harmonic and sag impact on PMSG wind turbines with a balancing new strategy for capacitor voltages," Energy Conversion and Management, vol. 79, pp. 721-730, March 2014.

[14] F.N. Eikland, "Compensation of wave-induced motion for marine crane operations," Science, Department of Engineering Cybernetics, Norwegian University, Trondheim, Norway, 2008.

[15] C.M. Ong, "Dynamic Simulation of Electric Machinery," Dynamic Simulation of Electric Machinery, New Jersey, 1998.

[16] T. Senjyu, S. Tamaki, N. Urasaki, and K. Uezato, "Wind velocity and position sensorless operation for PMSG wind generator," 5th Int. Conference on Power Electronics and Drive Systems, Singapore, vol. 1, pp. 787-792, November 2003.

[17] S. Khomfoi, and L.M. Tolbert, "Multilevel power converters" in: Power Electronics Handbook, 2nd ed, M.H. Rashid, Academic Press, USA, 2007, pp. 451-482.

[18] R. Melicio, "Modelação de sistema de conversão de energia eólica offshore integrado na rede elétrica," Lição de Síntese, Provas para obtenção do título académico de Agregação, Universidade de Évora, Évora, Portugal, 2014.

[19] J.D. Barros, and J.F. Silva, "Optimal predictive control of three-phase NPC multilevel converter for power quality applications," IEEE Trans. on Industrial Electronics, vol 55, pp. 3670-3681, October 2008.

[20] IEEE Guide for Harmonic Control and Reactive Compensation of Static Power Converters, IEEE Standard 519-1992. 